\title{
PERHITUNGAN ALOKASI DANA BAGI HASIL PAJAK ROKOK PADA BADAN PENGELOLA PENDAPATAN DAERAH PROVINSI JAWA TENGAH TRIWULAN IV TAHUN 2016
}

\author{
Akhsanur Rifai, Resi Yudhaningsih \\ Polines Jl. Prof Sudarto, SH Tembalang Semarang 50275 \\ Email : akhsanurrifai251095@gmail.com
}

\begin{abstract}
Abstrak: The reseach aims to know determine the procedure for calculating the allocation of funds from cigarette tax revenues quarter IV to Regency / City of Central Java Province On Central Java Regional Income Management Board. Writing method used are the method of description and exposition. The calculation of the allocation of revenue sharing funds for tobacco tax quarter $I V$ which is in use is the realization of 2016. The results of the calculating the allocation of funds from cigarette tax revenues quarter IV to Regency / City between of Central Java Province On Central Java Regional Income Management with regulation governer 67 in 2014 Show result different. Different because that the share of cigarette tax data the number of population used is the data of population in 2014, when it should be calculated with the data of the population in 2015.
\end{abstract}

Keywords: Allocation of profit sharing, cigarette tax, population data

\begin{abstract}
Abstrak: Penelitian ini bertujuan untuk mengetahui tata cara perhitungan alokasi dana bagi hasil penerimaan pajak rokok triwulan ke 4 kepada Kabupaten/Kota Provinsi Jawa Tengah Pada Badan Pengelola Pendapatan Daerah Provinsi Jawa Tengah. Metode penulisan yang digunakan adalah metode deskripsi dan eksposisi dengan teknik pengumpulan data melalui wawancara dan studi pustaka. Perhitungan alokasi dana bagi hasil penerimaan pajak rokok triwulan ke 4 Provinsi Jawa Tengah yang di gunakan dalam pembuatan Tugas akhir ini adalah realisasi tahun 2016. Hasil perhitungan alokasi dana bagi hasil penerimaan pajak rokok triwulan ke 4 antara Badan Pengelola Pendapatan Daerah Provinsi Jawa Tengah dengan Peraturan Gubernur Nomor 67 Tahun 2014 menunjukan hasil yang berbeda. Perbedaan tersebut disebabkan data jumlah penduduk yang digunakan Badan Pengelola Pendapatan Daerah Provinsi Jawa Tengah menggunakan data jumlah penduduk tahun 2014 yang seharusnya dihitung dengan data jumlah penduduk tahun 2015.
\end{abstract}

Kata kunci : Alokasi dana bagi hasil, pajak rokok, data jumlah penduduk 


\section{PENDAHULUAN}

Pembangunan daerah adalah proses yang dilakukan oleh pemerintah daerah bersama masyarakatnya dalam mengelola sumber daya yang ada menuju pada kondisi yang lebih baik. Dalam pelaksanaan pembangunan terdapat tiga pilar penyangga baik pembangunan secara fisik maupun penyelenggaraan pemerintahan. Ketiga Pilar tersebut dikenal dengan 3M yaitu : Man, Money dan Material (Sumber Daya Manusia, Uang dan Sarana Prasarana).

Perubahan paradigma pemerintahan seiring dengan pelaksanaan otonomi daerah, serta semakin kritisnya masyarakat menuntut adanya perencanaan yang lebih teliti, transparan, dan akuntabel sehingga kebijakan, program dan kegiatan yang akan dilaksanakan mampu memenuhi tuntutan dan kebutuhan masyarakat. Kondisi lingkungan external, baik secara global, regional, nasional maupun lokal pada berbagai situasi dan kondisi dapat dijadikan referensi dalam penyusunan strategi. Perubahan kondisi tersebut disatu sisi merupakan permasalahan dan disisi lain dapat pula menjadi suatu peluang. Untuk menjaga kesinambungan pelaksanaan pembangunan maka ketiga pilar tersebut yaitu Man, Money dan Material yang merupakan rangkaian mata rantai tidak terpisahkan perlu untuk terus ditingkatkan optimalisasi pengelolaan maupun pemanfaatannya dengan tetap memperhatikan prioritas penggunaan maupun pemanfaatannya. Badan Pengelolaan Pendapatan Daerah (BPPD) sebagai unsur pelaksana otonomi daerah di bidang Peningkatan Pendapatan Asli Daerah memiliki peran penting untuk mengoptimalkan Satu dari Tiga Pilar penyelenggaraan pemerintahan dan pembangunan, yaitu Money (uang/pendapatan), dimana salah satu sumbernya adalah pajak rokok yang brasal dari pajak daerah dan retribusi daerah. Definisi Pajak rokok menurut Undang-Undang Nomor 28 Tahun 2009 tentang Pajak Daerah dan
Retribusi Daerah Pasal 1 angka 1, pajak rokok adalah pungutan atas cukai rokok yang dipungut oleh pemerintah. Adanya Pembagian pajak pusat dan pajak daerah serta perluasan basis pajak daerah menimbulkan adanya kekhawatiran akan adanya pemungutan pajak ganda pada suatu objek yang sama yang dikenakan kepada subyek yang sama pula.

Pajak Daerah dan Retribusi di tetapkan dengan Undang-Undang yang pelaksanaanya di daerah diatur lebih lanjut dengan peraturan daerah. Dalam rangka menjalankan amanat Undang-Undang PDRD, Pemerintah Provinsi Jawa Tengah mengeluarkan Peraturan Daerah Provinsi Jawa Tengah Nomor 2 Tahun 2011 tentang Pajak Daerah Provinsi Jawa Tengah yang dalamnya berisi tentang aturan mengenai pajak rokok. Berbeda dengan pajak provinsi lainya yang diatur dalam peraturan daerah sendiri. Peraturan pajak rokok masih menjadi satu dengan peraturan tentang pajak daerah Provinsi Jawa Tengah yang terdapat pada pasal 72 sampai dengan pasal 83. Untuk melaksanakan ketentuan tersebut, maka di teteapkan Peraturan Gubernur Jawa Tengah Nomor 67 Tahun 2014 tentang Tata Cara Bagi Hasil Penerimaan Pajak Rokok kepada Kabupaten/Kota Provinsi Jawa Tengah. Peraturan Gubernur ini merupakan aturan pelaksana dari Peraturan Daerah Provinsi Jawa Tengah Nomor 2 Tahun 2011 tentang Pajak Daerah.

Kebijakan Pajak Rokok bertujuan untuk meningkatkan Pendapatan Asli Daerah (PAD). Pajak rokok juga bertujuan untuk mengendalikan konsumsi rokok, mengendalikan peredaran rokok ilegal, serta melindungi masyarakat atas bahaya rokok.

Berdasarkan Peraturan Gubernur Jawa Tengah Nomor 67 Tahun 2014 tentang Tentang Tata Cara Bagi Hasil Penerimaan Pajak Daerah kepada Kabupaten/Kota Provinsi Jawa Tengah, menyebutkan bahwa sebesar $70 \%$ realisasi pendapatan pajak rokok 
yang diperhitungkan dari rasio jumlah penduduk terbaru kabupaten/kota terhadap jumlah penduduk Provinsi Jawa Tengah.

Dalam tata cara bagi hasil tersebut sebagian hasil penerimaan pajak di bagikan kepada kabupaten/kota, untuk pajak rokok sebesar $70 \%$ persen berdasarkan realisasi yang di perhitungkan dari rasio jumlah penduduk kabupaten/kota terhadap jumlah penduduk Provinsi Jawa Tengah. Dan untuk 30\% persen secara tertimbang yang dibagi rata kepada kabupaten/kota. Dalam proses alokasi dana bagi hasil ke Rekening Kas Umum Daerah Provinsi Jawa Tengah masalah yang timbul dalam mendanai pelayanan masyarakat dari alokasi dana bagi hasil terhadap kabupaten/kota Provinsi Jawa Tengah yaitu adanya ketidaksesuaian dalam menerapkan data jumlah penduduk yang terakhir menurut Badan Pusat Statitik yang di atur dalam Peraturan Gubernur Nomor 67 Tahun 2014 Tentang Tata Cara Bagi Hasil Penerimaan Pajak Rokok kepada Kabupaten/Kota Provinsi Jawa Tengah. Sehingga menimbulkan selisih jumlah alokasi dana bagi hasil pajak rokok masing -masing Kabupaten/Kota

\section{METODE}

Jenis data yang digunakan dalam penulisan ini adalah menggunakan data sekunder meliputi gambaran umum mengenai Badan Pengelolaan Pendapatan Daerah Provinsi Jawa Tengah, Jumlah penduduk Kabupaten/Kota Provinsi Jawa Tengah. Adapun metode pengumpulan data yang digunakan adalah menggunakan metode wawancara melalui tanya jawab dengan bagian Retribusi Daerah serta studi pustaka dengan cara mencari tambahan informasi dari buku-buku dan literatur lainnya yang berhubungan dengan Pajak Daerah, Pendapatan Asli Daerah(PAD).

\section{HASIL DAN PEMBAHASAN DASAR PEMBAGIAN}

Menurut pasal 2 bahwa sebagian hasil penerimaan pajak daerah dibagihasilkan kepada Kabupaten/Kota berdasarkan atas penerimaan pada masing-masing Kabupaten/Kota. Penerimaan pajak rokok yang dibagikan ke Kabupaten/Kota adalah 70\% dari realisasi penerimaan pajak rokok masing-masing Kabupaten/Kota. Bagi Hasil Penerimaan Pajak Rokok yang dimaksud, dihitung dengan cara:

a. Sebesar $70 \%$ berdasarkan realisasi yang diperhitungkan dari rasio jumlah penduduk Kabupaten/Kota terhadap jumlah penduduk Provinsi Jawa Tengah, dimana data jumlah penduduk yang digunakan adalah data jumlah penduduk yang dikeluarkan oleh Badan Pusat Statistik.

b. Sebesar $30 \%$ secara tertimbang yang dibagi rata kepada Kabupatem/Kota.

c. Penyaluran bagi hasil penerimaan pajak rokok dilakukan setiap triwulan pada tahun anggaran berjalan sesuai ketentuan perundang-undangan.

d. Besaran alokasi dan bagi hasil perjenis paja untuk masingmasing Kabupaten/Kota pada Setiap tahun ditetapkan dengan Keputusan Gubernur.

e. Terhadap penerimaan pajak daerah sampai dengan tanggal 31 Desember tahun anggaran berjalan belum dapat diperhitungkan bagi hasilnya, maka bagi hasil penerimaan pajak daerah akan disalurkan pada tahun anggaran berjalan.

Mengetahui hasil perhitungan Badan Pengelola Pendapatan Daerah Provinsi Jawa Tengah dalam menerapkan data jumlah penduduk masih terdapat ketidaksesuaian dalam menggunakan jumlah penduduk yang terakhir dikeluarkan Badan Pusat Statistik. Realisasi Pendapatan bagi hasil Penerimaan pajak rokok Tahun 2016 yang seharusnya dihitung dengan jumah penduduk Tahun 2015 masih dihitung dengan Tahun 2014. Untuk 
lebih jelasnya dapat dilihat pada tabel 1 sampai tabel 7 dihtung dengan jumlah penduduk di tahun yang berbeda, untuk contoh perhitungan hanya menggunakan Kabupaten Semarang, Demak dan Kendal.

\section{Tabel 1}

Jumlah Penduduk Kabupaten/Kota Provinsi Jawa Tengah Tahun 2014

\begin{tabular}{|r|l|r|}
\hline NO & Kabupaten/Kota & $\begin{array}{c}\text { Jumlah } \\
\text { (jiwa) }\end{array}$ \\
\hline 1 & Kabupaten & \\
\hline 2 & Kendal & 987.597 \\
\hline 3 & Demak & 1.106 .209 \\
\hline 4 & Grobogan & 1.343 .985 \\
\hline 5 & Pati & 1.225 .603 \\
\hline 6 & Kudus & 821.109 \\
\hline 7 & Jepara & 1.170 .785 \\
\hline 8 & Rembang & 614.065 \\
\hline 9 & Blora & 848.387 \\
\hline 10 & Pekalongan & 867.701 \\
\hline 11 & Batang & 736.497 \\
\hline 12 & Pemalang & 1.284 .171 \\
\hline 13 & Tegal & 1.420 .106 \\
\hline 14 & Brebes & 1.773 .373 \\
\hline 15 & Banyumas & 1.620 .772 \\
\hline 16 & Cilacap & 1.685 .631 \\
\hline 17 & Purbalingga & 889.172 \\
\hline 18 & Banjarnegara & 896.038 \\
\hline 19 & Magelang & 1.233 .701 \\
\hline 20 & Temanggung & 738.881 \\
\hline 21 & Wonosobo & 773.391 \\
\hline
\end{tabular}

Tabel 2

PERHITUNGAN RASIO TERTIMBANG BAGI HASIL PAJAK ROKOK TAHUN ANGGARAN 2016

\begin{tabular}{|c|c|c|c|c|}
\hline \multirow{3}{*}{ NO } & \multirow{3}{*}{$\begin{array}{c}\text { KABUPATEN / } \\
\text { KOTA }\end{array}$} & \multicolumn{3}{|c|}{ PROPORSIONAL 70\% } \\
\hline & & $\begin{array}{l}\text { Penduduk } \\
\text { Provinsi } \\
\text { (jiwa) }\end{array}$ & $\begin{array}{c}\text { Penduduk } \\
\text { Kab./Kota } \\
\text { (jiwa) }\end{array}$ & $\begin{array}{c}\text { Rasio Penduduk } \\
\text { Kab/Kota dengan } \\
\text { Provinsi }\end{array}$ \\
\hline & & 33.522 .663 & 33.522 .663 & 1,00 \\
\hline \multirow[t]{2}{*}{1} & 2 & 3 & 4 & $5=4 / 3$ \\
\hline & KABUPATEN & & & \\
\hline 1 & Semarang & & 987.557 & 0,0294593839397544 \\
\hline 2 & Kendal & & 934.643 & 0,0278809293879785 \\
\hline
\end{tabular}

\begin{tabular}{|r|l|r|}
\hline 22 & Purworejo & 708.006 \\
\hline 23 & Kebumen & 1.180 .894 \\
\hline 24 & Klaten & 1.154 .028 \\
\hline 25 & Boyolali & 957.913 \\
\hline 26 & Sragen & 875.615 \\
\hline 27 & Sukoharjo & 856.861 \\
\hline 28 & Karanganyar & 848.326 \\
\hline 29 & Wonogiri & 945.682 \\
\hline & Kota & \\
\hline 30 & Semarang & 1.672 .994 \\
\hline 31 & Pekalongan & 293.178 \\
\hline 32 & Surakarta & 510.105 \\
\hline 33 & Salatiga & 181.304 \\
\hline 34 & Tegal & 244.978 \\
\hline 35 & Magelang & 120.438 \\
\hline & Jumlah & 33.522 .663 \\
\hline
\end{tabular}

Sumber : Badan Pusat Statistik Provinsi Jawa Tengah, Tahun 2014

Tabel di atas menunjukan jumlah penduduk tahun 2014 Kabupaten/Kota Provinsi Jawa Tengah yang di gunakan untuk mencari rasio tertimbang jumlah penduduk tahun 2014 Kabupaten/Kota Provinsi Jawa Tengah. Hasil perhitungan rasio tertimbang jumlah penduduk tahun 2014 tersebut nantinya akan menentukan jumlah penerimaan dana bagi hasil pajak rokok masing- masing Kabupaten/Kota Provinsi Jawa Tengah. 


\begin{tabular}{|c|c|c|c|}
\hline 3 & Demak & 1.106 .328 & 0,0330023900547519 \\
\hline 4 & Grobogan & 1.343 .960 & 0,0400910870356570 \\
\hline 5 & Pati & 1.225 .594 & 0,0365601622997552 \\
\hline 6 & Kudus & 821.136 & 0,0244949513706593 \\
\hline 7 & Jepara & 1.170 .797 & 0,0349255367928258 \\
\hline 8 & Rembang & 614.087 & 0,0183185625795898 \\
\hline 9 & Blora & 848.369 & 0,0253073271655059 \\
\hline 10 & Pekalongan & 867.573 & 0,0258801933486012 \\
\hline 11 & Batang & 736.397 & 0,0219671390664876 \\
\hline 12 & Pemalang & 1.284 .236 & 0,0383094863316796 \\
\hline 13 & Tegal & 1.420 .132 & 0,0423633408837478 \\
\hline 14 & Brebes & 1.773 .379 & 0,0529008987144011 \\
\hline 15 & Banyumas & 1.620 .918 & 0,0483529008420363 \\
\hline 16 & Cilacap & 1.685 .573 & 0,0502815960653245 \\
\hline 17 & Purbalingga & 889.214 & 0,0265257566202303 \\
\hline 18 & Banjarnegara & 895.986 & 0,0267277692109365 \\
\hline 19 & Magelang & 1.233 .695 & 0,0368018197122347 \\
\hline 20 & Temanggung & 738.915 & 0,0220422524308406 \\
\hline 21 & Wonosobo & 773.280 & 0,0230673798200340 \\
\hline 22 & Purworejo & 708.038 & 0,0211211740546985 \\
\hline 23 & Kebumen & 1.181 .006 & 0,0352300770377341 \\
\hline 24 & Klaten & 1.154 .040 & 0,0344256660039210 \\
\hline 25 & Boyolali & 957.857 & 0,0285734161394040 \\
\hline 26 & Sragen & 875.600 & 0,0261196432992212 \\
\hline 27 & Sukoharjo & 856.937 & 0,0255629154521525 \\
\hline 28 & Karanganyar & 848.255 & 0,0253039264810197 \\
\hline 29 & Wonogiri & 945.817 & 0,0282142561287568 \\
\hline
\end{tabular}




\begin{tabular}{|c|l|r|c|}
\hline & Kota & & \\
\hline 30 & Semarang & 1.672 .999 & 0,0499065065326105 \\
\hline 31 & Pekalongan & 293.704 & 0,0087613564590617 \\
\hline 32 & Surakarta & 510.077 & 0,0152158854444231 \\
\hline 33 & Salatiga & 181.193 & 0,0054050896851482 \\
\hline 34 & Tegal & 244.998 & 0,0073084289276183 \\
\hline 35 & Magelang & 120.373 & 0,0035907946811982 \\
\hline \multicolumn{2}{|c|}{ Jumlah } & 33.522 .663 & 1,00 \\
\hline
\end{tabular}

Sumber : Data Sekunder yang diolah, Tahun 2017

Tabel di atas menunjukan rasio tertimbang jumlah penduduk tahun 2014 Kabupaten/Kota Provinsi Jawa Tengah yang di gunakan untuk menghitung dana bagi hasil penerimaan pajak rokok triwulan 4 tahun 2016 setelah mengetahui jumlah penduduk masing-masing Kabupaten/Kota Provinsi Jawa Tengah. 
Tabel 3

PERHITUNGAN BAGI HASIL PAJAK ROKOK PROVINSI JAWA TENGAH

KEPADA KABUPATEN / KOTA TRIWULAN IV (EMPAT) TA. 2016

Realisasi Pajak Rokok TW $4: 303.199 .996 .600$

*dalam rupiah

\begin{tabular}{|c|c|c|c|c|c|c|c|}
\hline \multirow{4}{*}{ o. } & \multirow{4}{*}{$\begin{array}{l}\text { KABUPATEN/ } \\
\text { KOTA }\end{array}$} & \multirow{3}{*}{$\begin{array}{c}\text { BAGIAN } \\
\text { KAB./KOTA } \\
70 \% \text { DARI } \\
\text { REALISASI } \\
\end{array}$} & \multicolumn{3}{|c|}{ RINCIAN BAGIAN KAB/KOTA } & \multirow{4}{*}{$\begin{array}{l}\text { JUMLAH BAGI } \\
\text { HASIL } \\
\text { PAJAK ROKOK }\end{array}$} & \multirow{4}{*}{$\begin{array}{c}\text { BAGI HASIL } \\
\text { PAJAK } \\
\text { ROKOK } \\
\text { (PEMBULATA } \\
\text { N) }\end{array}$} \\
\hline & & & \multicolumn{2}{|c|}{70 \% PROPORSIONAL } & $\begin{array}{c}30 \% \\
\text { TERTIMBAN }\end{array}$ & & \\
\hline & & & \multirow{2}{*}{$\begin{array}{l}\text { Bobot (Rasio pddk } \\
\text { Kab/Kota thdp } \\
\text { Prov.) }\end{array}$} & \multirow{2}{*}{$70 \%$} & \multirow{2}{*}{ BAGI RATA } & & \\
\hline & & $\begin{array}{c}212.239 .997 .6 \\
20,00\end{array}$ & & & & & \\
\hline \multirow[t]{2}{*}{1} & 2 & 3 & 4 & $5=3 \times 4 \times 70 \%$ & 6 & $7=5+6$ & 8 \\
\hline & KABUPATEN & & & & & & \\
\hline 1 & SEMARANG & $\begin{array}{r}212.239 .997 .6 \\
20,00 \\
\end{array}$ & $\begin{array}{r}0,029634713729654 \\
9 \\
\end{array}$ & $\begin{array}{r}4.402 .770 .100,0 \\
2 \\
\end{array}$ & $\begin{array}{r}1.819 .199 .979 \\
60 \\
\end{array}$ & $6.221 .970 .079,62$ & 6.221 .970 .080 \\
\hline 2 & KENDAL & $\begin{array}{r}212.239 .997 .6 \\
20,00\end{array}$ & $\begin{array}{r}0,027899540065282 \\
5\end{array}$ & $\begin{array}{r}4.144 .978 .821,9 \\
4\end{array}$ & $\begin{array}{r}1.819 .199 .979 \\
60 \\
\end{array}$ & $5.964 .178 .801,54$ & 5.964 .178 .802 \\
\hline 3 & DEMAK & $\begin{array}{r}212.239 .997 .6 \\
20,00 \\
\end{array}$ & $\begin{array}{r}0,033099435452703 \\
3 \\
\end{array}$ & $\begin{array}{r}4.917 .516 .871,1 \\
9 \\
\end{array}$ & $\begin{array}{r}1.819 .199 .979 \\
60 \\
\end{array}$ & $6.736 .716 .850,79$ & 6.736.716.851 \\
\hline
\end{tabular}

Setelah mengetahui jumlah penduduk dan rasio tertimbang jumlah penduduk tahun 2014, tabel di atas merupakan hasil dari perhitungan $30 \%$ secara tertimbang dan $70 \%$ secara proporsional dimana perhitungan ini terdapat ketidaksesuaian dalam menggunakan jumlah penduduk. 
Tabel 4

Jumlah Penduduk Kabupaten/Kota Provinsi Jawa

\begin{tabular}{|r|l|r|}
\hline NO & Kabupaten/Kota & $\begin{array}{c}\text { Jumlah } \\
\text { (jiwa) }\end{array}$ \\
\hline & Kabupaten & \\
\hline 1 & Semarang & 1.000 .887 \\
\hline 2 & Kendal & 942.283 \\
\hline 3 & Demak & 1.117 .905 \\
\hline 4 & Grobogan & 1.351 .429 \\
\hline 5 & Pati & 1.232 .889 \\
\hline 6 & Kudus & 831.303 \\
\hline 7 & Jepara & 1.188 .289 \\
\hline 8 & Rembang & 619.173 \\
\hline 9 & Blora & 852.108 \\
\hline 10 & Pekalongan & 873.986 \\
\hline 11 & Batang & 743.090 \\
\hline 12 & Pemalang & 1.288 .577 \\
\hline 13 & Tegal & 1.424 .891 \\
\hline 14 & Brebes & 1.781 .379 \\
\hline 15 & Banyumas & 1.635 .909 \\
\hline & & \\
\hline 16 & Cilacap & 1.694 .726 \\
\hline 17 & Purbalingga & 898.376 \\
\hline 18 & Banjarnegara & 901.826 \\
\hline 19 & Magelang & 1.245 .496 \\
\hline 20 & Temanggung & 745.825 \\
\hline 21 & Wonosobo & 777.122 \\
\hline 22 & Purworejo & 710.386 \\
\hline 23 & Kebumen & 1.184 .882 \\
\hline
\end{tabular}

\begin{tabular}{|c|c|c|}
\hline 24 & Klaten & 1.158 .795 \\
\hline 25 & Boyolali & 743.090 \\
\hline 26 & Sragen & 879.027 \\
\hline 27 & Sukoharjo & 864.207 \\
\hline 28 & Karanganyar & 856.198 \\
\hline \multirow[t]{2}{*}{29} & Wonogiri & 949.017 \\
\hline & Kota & \\
\hline 30 & Semarang & 1.701 .114 \\
\hline 31 & Pekalongan & 296.404 \\
\hline 32 & Surakarta & 183.815 \\
\hline 33 & Salatiga & 183.815 \\
\hline 34 & Tegal & 246.119 \\
\hline 35 & Magelang & 120.792 \\
\hline & & 33.774 .141 \\
\hline
\end{tabular}

Sumber : Badan Pusat Statistik Provinsi Jawa Tengah, Tahun 2015

Tabel di atas adalah jumlah penduduk tahun 2015 Kabupaten/Kota Provinsi Jawa Tengah yang di gunakan untuk mencari rasio tertimbang jumlah penduduk tahun 2015 Kabupaten/Kota Provinsi Jawa Tengah. Hasil perhitungan rasio tertimbang jumlah penduduk nantinya yang akan menentukan jumlah penerimaan dana bagi hasil pajak rokok pada masingmasing Kabupaten/Kota Provinsi Jawa Tengah setelah dihitung dengan realisasi.

Tabel 5

PERHITUNGAN BOBOT TERTIMBANG BAGI HASIL PAJAK ROKOK TAHUN ANGGARAN 2016

\begin{tabular}{|c|c|c|c|c|}
\hline \multirow{3}{*}{$\begin{array}{l}\mathrm{N} \\
\mathrm{O}\end{array}$} & \multirow{3}{*}{ KABUPATEN / KOTA } & \multicolumn{3}{|c|}{ PROPORSIONAL 70\% } \\
\hline & & $\begin{array}{c}\text { Penduduk } \\
\text { Provinsi } \\
\text { (jiwa) }\end{array}$ & $\begin{array}{c}\text { Penduduk } \\
\text { Kab./Kota } \\
\text { (jiwa) }\end{array}$ & $\begin{array}{c}\text { Rasio Penduduk Kab/Kota } \\
\text { dengan Provinsi }\end{array}$ \\
\hline & & 33.774 .141 & 33.774 .141 & 1,00 \\
\hline 1 & 2 & 3 & 4 & $5=4 / 3$ \\
\hline & Kabupaten & & & \\
\hline 1 & Semarang & & 1.000 .887 & 0,0296347137296549 \\
\hline 2 & Kendal & & 942.283 & 0,0278995400652825 \\
\hline 3 & Demak & & 1.117 .905 & 0,0330994354527033 \\
\hline
\end{tabular}




\begin{tabular}{|c|c|c|c|}
\hline 4 & Grobogan & 1.351 .429 & 0,0400137193718709 \\
\hline 5 & Pati & 1.232 .889 & 0,0365039335863494 \\
\hline 6 & Kudus & 831.303 & 0,0246135941695749 \\
\hline 7 & Jepara & 1.188 .289 & 0,0351833966702514 \\
\hline 8 & Rembang & 619.173 & 0,0183327534518198 \\
\hline 9 & Blora & 852.108 & 0,0252295979933287 \\
\hline 10 & Pekalongan & 873.986 & 0,0258773716850415 \\
\hline 11 & Batang & 743.090 & 0,0220017438785490 \\
\hline 12 & Pemalang & 1.288 .577 & 0,0381527690075078 \\
\hline 13 & Tegal & 1.424 .891 & 0,0421888154017004 \\
\hline 14 & Brebes & 1.781 .379 & 0,0527438728937621 \\
\hline 15 & Banyumas & 1.635 .909 & 0,0484367315219061 \\
\hline 16 & Cilacap & 1.694 .726 & 0,0501782117863486 \\
\hline 17 & Purbalingga & 898.376 & 0,0265995218057507 \\
\hline 18 & Banjarnegara & 901.826 & 0,0267016709618166 \\
\hline 19 & Magelang & 1.245 .496 & 0,0368772073285298 \\
\hline 20 & Temanggung & 745.825 & 0,0220827229921258 \\
\hline 21 & Wonosobo & 777.122 & 0,0230093786841240 \\
\hline 22 & Purworejo & 710.386 & 0,0210334290959465 \\
\hline 23 & Kebumen & 1.184 .882 & 0,0350825206775799 \\
\hline 24 & Klaten & 1.158 .795 & 0,0343101250154667 \\
\hline 25 & Boyolali & 963.690 & 0,0285333681765585 \\
\hline 26 & Sragen & 879.027 & 0,0260266278867018 \\
\hline 27 & Sukoharjo & 864.207 & 0,0255878306423841 \\
\hline 28 & Karanganyar & 856.198 & 0,0253506965580561 \\
\hline \multirow[t]{2}{*}{29} & Wonogiri & 949.017 & 0,0280989233745427 \\
\hline & Kota & & - \\
\hline
\end{tabular}




\begin{tabular}{|c|c|c|c|}
\hline 30 & Semarang & 1.701 .114 & 0,0503673505715512 \\
\hline 31 & Pekalongan & 296.404 & 0,0087760633201597 \\
\hline 32 & Surakarta & 512.226 & 0,0151662184391307 \\
\hline 33 & Salatiga & 183.815 & 0,0054424774267390 \\
\hline 34 & Tegal & 246.119 & 0,0072872023599357 \\
\hline 35 & Magelang & 120.792 & 0,0035764640172492 \\
\hline \multicolumn{2}{|r|}{ Jumlah } & 33.774 .141 & 1,00 \\
\hline
\end{tabular}

Sumber : Data Sekunder yang diolah, Tahun 2017

Tabel di atas merupakan rasio tertimbang jumlah penduduk tahun 2015 Kabupaten/Kota Provinsi Jawa Tengah yang di gunakan untuk menghitung dana bagi hasil penerimaan pajak rokok triwulan 4 tahun 2016 setelah mengetahui jumlah penduduk masing-masing Kabupaten/Kota Provinsi Jawa Tengah. Rasio tertimbang jumlah penduduk tahun 2015 ini diperoleh sesuai dengan Peraturan Gubernur nomor 67 tahun 2014. 
Tabel 6

PERHITUNGAN BAGI HASIL PAJAK ROKOK PROVINSI JAWA TENGAH MENURUT PERATURAN GUBERNUR KEPADA KABUPATEN / KOTA TRIWULAN IV (EMPAT) TA. 2016

Realisasi Pajak Rokok TW 4:303.199.996.600

*dalam rupiah

\begin{tabular}{|c|c|c|c|c|c|c|c|}
\hline \multirow{4}{*}{ No. } & \multirow{4}{*}{$\begin{array}{c}\text { KABUPATEN } \\
\text { / KOTA }\end{array}$} & \multirow{3}{*}{$\begin{array}{c}\text { BAGIAN } \\
\text { KAB./KOTA } \\
70 \% \text { DARI } \\
\text { REALISASI } \\
\end{array}$} & \multicolumn{3}{|c|}{ RINCIAN BAGIAN KAB/KOTA } & \multirow{4}{*}{$\begin{array}{l}\text { JUMLAH BAGI } \\
\text { HASIL } \\
\text { PAJAK ROKOK }\end{array}$} & \multirow{4}{*}{$\begin{array}{l}\text { BAGI HASIL } \\
\text { PAJAK ROKOK } \\
\text { (PEMBULATAN) }\end{array}$} \\
\hline & & & \multicolumn{2}{|c|}{$70 \%$ PROPORSIONAL } & \multirow{3}{*}{$\begin{array}{c}30 \% \\
\text { TERTIMBAN } \\
\text { G } \\
\\
\text { BAGI RATA }\end{array}$} & & \\
\hline & & & \multirow{2}{*}{$\begin{array}{l}\text { Bobot (Rasio } \\
\text { pddk Kab/Kota } \\
\text { thdp Prov.) }\end{array}$} & \multirow{2}{*}{$70 \%$} & & & \\
\hline & & $\begin{array}{c}212.239 .997 .62 \\
0,00 \\
\end{array}$ & & & & & \\
\hline \multirow[t]{2}{*}{1} & 2 & 3 & 4 & $5=3 \times 4 \times 70 \%$ & 6 & $7=5+6$ & 8 \\
\hline & $\begin{array}{l}\text { KABUPAT } \\
\text { EN }\end{array}$ & & & & & & \\
\hline 1 & $\mathrm{G}^{\text {SEMARAN }}$ & $\begin{array}{r}212.239 .997 .62 \\
0,00\end{array}$ & $\begin{array}{r}0,029634713729 \\
6549\end{array}$ & $\begin{array}{r}4.402 .770 .10 \\
0,02\end{array}$ & $\begin{array}{r}1.819 .199 .979 \\
, 60 \\
\end{array}$ & $6.221 .970 .079,62$ & 6.221 .970 .080 \\
\hline 2 & KENDAL & $\begin{array}{r}212.239 .997 .62 \\
0,00\end{array}$ & $\begin{array}{r}0,027899540065 \\
2825\end{array}$ & $\begin{array}{r}4.144 .978 .82 \\
1,94\end{array}$ & $\begin{array}{r}1.819 .199 .979 \\
, 60 \\
\end{array}$ & $5.964 .178 .801,54$ & 5.964 .178 .802 \\
\hline 3 & DEMAK & $\begin{array}{r}212.239 .997 .62 \\
0,00\end{array}$ & $\begin{array}{r}0,033099435452 \\
7033\end{array}$ & $\begin{array}{r}4.917 .516 .87 \\
1,19\end{array}$ & $\begin{array}{r}1.819 .199 .979 \\
, 60\end{array}$ & $6.736 .716 .850,79$ & 6.736 .716 .851 \\
\hline
\end{tabular}

Sumber : Data Sekunder yang diolah, 2017

Setelah mengetahui jumlah penduduk dan rasio tertimbang jumlah penduduk tahun 2014, tabel di atas merupaakan hasil dari perhitungan $30 \%$ secara tertimbang dan $70 \%$ secara proporsional dimana perhitungan ini sudah sesuai dalam Peraturan Gubernur Nomor 67 Tahun 2014. 
Tabel 7

REKAPITULASI DANA BAGI HASIL PENERIMAAN PAJAK ROKOK TRIWULAN KE

4 TAHUN 2016

\begin{tabular}{|r|l|c|c|c|}
\hline NO & KABUPATEN & $\begin{array}{c}\text { MENURUT BADAN } \\
\text { PENGELOLA PENDAPATAN } \\
\text { DAERAH PROVINSI JAWA } \\
\text { TENGAAH }\end{array}$ & $\begin{array}{c}\text { MENURUT } \\
\text { PERATURAN } \\
\text { GUBERNUR NO 67 } \\
\text { TAHUN 2014 }\end{array}$ & SELISIH \\
\hline 1 & Semarang & 6.195 .921 .684 & 6.221 .970 .080 & $26.048 .395,62$ \\
\hline 2 & Kendal & 5.961 .413 .851 & 5.964 .178 .802 & $2.764 .950,54$ \\
\hline 3 & Demak & 6.722 .299 .010 & 6.736 .716 .851 & $14.417 .840,79$ \\
\hline
\end{tabular}

Sumber : Data Sekunder yang diolah, Tahun 2017

Berdasarkan rekapitulasi hasil perhitungan dana bagi hasil penerimaan pajak rokok triwulan ke 4 Tahun 2016 pada Kabupaten Semarang, Demak dan Kendal, perhitungan antara Badan Pengelola Pendapatan Daerah dengan menurut Peraturan Gubernur Peraturan Nomor 67 Tahun 2014 terjadi perbedaan. Perbedaan tersebut karena Badan Pengelola Pendapatan Daerah Provinsi Jawa Tengah masih mennggunakan data jumlah penduduk Tahun 2014 sementara seharusnya dihitung dengan jumlah penduduk Tahun 2015.

\section{KESIMPULAN}

a) Berdasarkan Peraturan Gubernur Tentang Tata Cara Bagi Hasil Penerimaan Pajak Daerah Provinsi Jawa Tengah, perhitunganya yaitu bahwa $\quad 70 \%$ dari realisasi pendapatan pajak rokok dibagikan kepada Kabupaten/Kota, dimana $70 \%$ dibagikan secara proporsional berdasarkan rasio jumlah penduduk Kabupaten/Kota terhadap jumlah penduduk Provinsi Jawa Tengah dan $30 \%$ dibagikan secara tertimbang.

b) Mengacu pada Pasal 6 ayat 2 menyebutkan bahwa data jumlah penduduk yang digunakan adalah data jumlah penduduk terakhir yang dikeluarkan Badan Pusat
Statistik Provinsi Jawa Tengah, sementara Badan Pengelola Pendapatan Daerah Provinsi Jawa Tengah dalam menghitung tata cara dana bagi penerimaan hasil pajak rokok pada triwulan ke 4 tahun 2016 masih menggunakan data jumlah penduduk tahun 2014 . Seharusnya perhitungan tata cara penerimaan dana bagi hasil pajak rokok triwulan ke 4 tahun 2016 menggunakan data jumlah penduduk tahun 2015.Sehingga dapat dikatan bahwa Badan Pengelola Pendapatan Daerah Provinsi Jawa Tengah dalam menerapkan Peraturan tersebut belum sesuai dan mengakibatkan jumlah penerimaan dana bagi hasil pajak rokok triwulan ke 4 berbeda.

\section{DAFTAR PUSTAKA}

Alek dan Achmad H.P.. 2011. Bahasa Indonesia Untuk Perguruan Tinggi. Jakarta: Kencana

Bungin,Burhan. 2013. Metodologi Penelitian Sosial \& Ekonomi Format Kuantitatif dan kualitatif untuk studi sosiologi kebijakan pubilk komunikasi manajemen dan Pemasaran. Jakarta : PT Kencana Perdana Media Group.

Mardiasmo. 2016. Perpajakan. Yogyakarta: Andi. 
Provinsi Jawa Tengah. Peraturan Gubernur Nomor 67 Tahun 2014 tentang Alokasi Dana Bagi Hasil Pajak Daerah

Provinsi Jawa Tengah. Sumber Badan Pengelola Pendapatan Daerah Provinsi Jawa Tengah 2017 “ Rencana Strategi"

Peraturan Menteri Keuanagan Republik Indonesia 11/pmk.07/2013" Tata Cara Pemungutan dan Penyetoran pajak rokok"
Renstra, 2017” Rencana Strategi Badan Pengelola Pendapatan Daerah Provinsi Jawa Tengah"

Sujarweni, V, Wiratna. 2015. Metode Penelitian Bisnis dan Ekonomi

Undang-Undang Nomor 28 Tahun 2009 tentang Pajak Daerah Provinsi dan Kabupaten/Kota.

Suratno dan Lincolin. 2008. Metode Penelitian Bisnis \& Ekonomi. Yogyakarta: Sekolah Tinggi Ilmu Manajemen YKPN. 